\title{
Biomarker-based H-Print quantifies the composition of mixed sympagic and pelagic algae consumed by Artemia sp.
}

\section{Brown, Thomas}

http://hdl.handle.net/10026.1/8243

\subsection{6/j.jembe.2016.12.007 \\ Journal of Experimental Marine Biology and Ecology \\ Elsevier BV}

All content in PEARL is protected by copyright law. Author manuscripts are made available in accordance with publisher policies. Please cite only the published version using the details provided on the item record or document. In the absence of an open licence (e.g. Creative Commons), permissions for further reuse of content should be sought from the publisher or author. 
Biomarker-based H-Print quantifies the composition of mixed sympagic and pelagic algae consumed by Artemia sp.

\section{Thomas A. Brown ${ }^{*}, 1$ and Simon T. Belt}

(1)

School of Geography, Earth and Environmental Sciences, University of Plymouth, Plymouth, UK, PL4 8AA

* Corresponding author: thomas.brown@ sams.ac.uk

${ }^{1}$ Current address: Department of Marine Ecology and Chemistry, Scottish Association for Marine Science, Oban, UK, PA37 1QA. (Thomas.Brown@sams.ac.uk)

\section{Abstract}

Quantifying the importance of sea ice microalgae as a food source in Arctic ecosystems is becoming an increasingly important research objective as sea ice extent and thickness continue to reduce. Recently, the analysis of certain diatom-derived highly branched isoprenoid (HBI) lipid biomarkers has provided a means of qualitatively distinguishing between sympagic (sea ice) and pelagic algae in Arctic animals. By combining the abundances of these lipids into an HBI-fingerprint, or "H-Print", an estimate of the relative proportions of HBIs from each algal source can also be made. Although H-Print analysis of animal tissues in the Arctic is starting to provide such information, it has not yet been established to what extent H-Prints in animals provide a true reflection of the content of their algal food source. Here it is demonstrated that the H-Print determination can yield reliable 
estimates of mixed sympagic/pelagic algal content both within a food source of known composition, and in a primary consumer fed on it. In doing so, the utility of the H-Print is extended towards providing quantitative estimates of the relative importance of sympagic algae to animal diet. To achieve this, a series of 5 algal samples were prepared with known $\%$ sympagic algal content ranging from 0 to $100 \%$. Analysis of these samples led to a comparison of different regression models based upon H-Prints using 4 different combinations of individual HBIs. A linear model comprising 3 HBIs (2 sympagic and 1 pelagic) provided the most accurate estimates of the sympagic content $(-1 \%, 50 \%$ and $101 \%)$ for samples containing $0 \%, 50 \%$ and $100 \%$ sympagic algae. This linear model was then used to estimate the proportion of sympagic algae in Artemia sp. $(-3 \%, 44 \%$ and $101 \%)$ fed on the same algal mixtures in the laboratory. The similarity between H-Prints in mixed algae and Artemia sp. suggested that H-Prints were not altered substantially by grazing, and this was also confirmed by analysis of the remaining water (containing ungrazed algae and faecal pellets), where H-Prints were not significantly different from those obtained for the algae or Artemia sp. $(p=>0.3)$. This study has extended the usefulness of the H-Print as an approach to determine ecosystem change in the future. Indeed, the ability of the H-Print to provide quantitative estimates of the importance of sympagic algae to Arctic animals is likely to result in valuable data that can be used for modelling the broader ecological impact of reducing sea ice extent.

Keywords: Highly branched isoprenoid (HBI), H-Print, sea ice algae, sympagic carbon, foodweb, Arctic 
1 Introduction

Arctic sea ice provides a habitat for ice-adapted microalgae (Dieckmann and Hellmer, 2010), which, in turn, provide food for a wide range of heterotrophic organisms (Arrigo, 2014). With Arctic sea ice extent reducing (Meier et al., 2014; Stroeve et al., 2012), there is a need to understand the impact of an associated reduction in sea ice microalgae as they provide an important energy source for the ecosystem (Arrigo, 2014). Fundamental to this understanding is being able to ascertain, quantitatively, the sympagic and pelagic components of an animal's diet. In order for this to be achieved, however, it is first necessary to be able to identify methods by which sympagic and pelagic algae can be both distinguished and quantified. Such methods may, potentially, be available through the identification of signature chemical tracers of each algal type.

Highly branched isoprenoid (HBI) lipids are secondary metabolites that have been reported in a number of marine diatom genera that regularly form components of both sympagic and pelagic algae. For instance, in the Arctic, the sea ice diatoms Haslea crucigeroides, $H$. spicula, H. kjellmanii and Pleurosigma stuxbergii var rhomboides biosynthesise certain HBIs (e.g. I and III; Fig. 1.; Brown et al., 2014c) that have a distinctive carbon isotopic composition when found in the environment $\left(\delta^{13} \mathrm{C}=-19 \pm 2 \%\right.$ and $-18 \pm 1 \%$; Belt et al., 2008). While these sympagic HBIs are regularly reported in samples of Arctic sea ice (Belt et al., 2007, 2013; Brown et al., 2011), surface (Belt and Müller, 2013; Navarro-Rodriguez et al., 2013; Smik et al., 2016; Stoynova et al., 2013; Xiao et al., 2015) and downcore (Belt et al., 2015; Müller et al., 2009,2012; Polyak et al., 2016; Stein et al., 2016; Vare et al., 2009) sediments, as yet, they have not been found in pelagic water samples from ice-free locations. In contrast, other HBIs (including, II, IV, V, VI, VII and VIII; Fig. 1) are frequently reported 
within pelagic water samples from sub-polar and temperate regions (Belt, et al. 2000; Cooke et al., 1998; Dunlop and Jefferies, 1985; He et al., 2016; Kaiser et al., 2016; Xu et al., 2006), and represent common components of marine sediments worldwide (Belt et al., 2000). These pelagic HBIs have been shown to be biosynthesised by temperate diatoms including Berkeleya rutilans (Brown et al., 2014b), H. ostrearia (Volkman et al., 1994; Wraige et al., 1997), Pseudosolenia calcar-avis (Kaiser et al., 2016), Pleurosigma intermedium (Belt et al., 2000; Brown and Belt, 2016), P. strigosum (Grossi et al., 2004) and Rhizosolenia setigera (Rowland et al., 2001; Volkman et al., 1994), making them ideal indicators of pelagic algae. The HBI biomarker-based H-Print (Brown et al., 2014d) provides a means of numerically combining all of these HBI biomarker abundances into a single index, thereby providing a measure of the relative composition of sympagic and pelagic algae in a sample of mixed content. While end-member H-Print values from sympagic and pelagic algae are relatively straightforward to interpret (Brown et al., 2014a,d), as yet, it has not been established whether intermediate values of the H-Print accurately reflect the relative proportions of mixed sympagic/pelagic algae composition.

The main aim of the current study, therefore, was to identify a numerical model that described the relationship between the H-Print and the proportion of sympagic and pelagic algae for samples created in the laboratory. To achieve this, HBIs were first quantified in a series of samples made by combining varying proportions of both sympagic and pelagic algae. The abundances of various HBI biomarkers were then combined to produce H-Print values, which were subsequently used to establish a regression model. Further, in order to test the applicability of the H-Print approach within an animal grazing context, H-Prints derived from analysis of algal food sources of known composition were compared with those obtained from Artemia sp. fed on the same samples. 
2 Material and methods

2.1 Diatom composition of sympagic and pelagic algae samples

For the determination of H-Print values in sympagic algae, samples of floating sea ice algae aggregates were used that had been collected from Resolute Bay, Nunavut, Canada (Brown et al., 2014c). Aggregates contained the HBI biosynthesising sea ice diatoms H. crucigeroides, H. spicula, H. kjellmanii, P. stuxbergii var rhomboides (combined total ca. 2\%), with the remainder comprising mainly (ca. 80\%) Navicula pelagica, Pauliella taeniata and Nitzschia frigida (Brown et al., 2014c). Samples to represent pelagic algae were prepared by combining cultures of known temperate HBI biosynthesising diatom species (P. intermedium (ca. 1\%), P. planktonicum (ca. 0.5\%), P. sp. (ca. 1\%) and H. ostrearia (ca. 2\%)) with a non-HBI producing centric diatom (Thalassiosira weisfloggi; ca. 95\%). Total diatom cell abundances in $10 \mathrm{mg}$ subsamples were comparable for both sympagic $\left(3.1 \times 10^{6}\right.$ cell $\left.\mathrm{L}^{-1}\right)$ and pelagic $(3.5$ $\mathrm{x} 10^{6}$ cell $\left.\mathrm{L}^{-1}\right)$ algae.

\subsection{Rearing and feeding of Artemia sp. - experimental setup}

For feeding experiments, Artemia sp. were chosen since the Artemiidae are considered to be continuous, non-selective filter feeders (Evjemo and Olsen, 1999), reaching saturated ingestion capacity between $2 \times 10^{3}$ and $1 \times 10^{4}$ cells L ${ }^{-1}$ (da Costa et al., 2005; Reeve, 1963), which is below the cell abundances used here. About 1000 decapsulated Artemia sp. eggs (Waterlife Research ind. Ltd.) were rinsed with deionised water (ca. $10 \mathrm{~mL}$ ), transferred to 1.5 L clear plastic flasks (Corning) containing artificial seawater with a salinity of $32(1 \mathrm{~L}$ milli-Q water; $32 \mathrm{~g}$ TropicMarin ${ }^{\circledR}$ salt), and maintained in suspension by aeration. During 
rearing, light intensity was maintained below $1 \mu \mathrm{mol}$ photons $\mathrm{m}^{-2} \mathrm{~s}^{-1}$. From 3 days after hatching, a regime of $100 \%$ water changes, immediately followed by feeding (ca. $0.5 \mathrm{~g}$ $\mathrm{H}^{2}$ Ocean $\left.{ }^{\text {Pro+ }}\right)$, was carried out every 2-3 days. At $>40$ days old, 20 individual Artemia sp. were selected randomly from the rearing stock and transferred, along with $10 \mathrm{mg}$ algae, to experimental flasks containing artificial seawater. Experimental flasks were maintained at $20 \pm 2.5^{\circ} \mathrm{C}$ and ca. $2 \mu \mathrm{mol}$ photons $\mathrm{m}^{-2} \mathrm{~s}^{-1}$, with algae sustained in suspension by vigorous aeration. After feeding on algae for $24 \mathrm{~h}$, Artemia sp. were removed from the water using a plastic pipette and pooled $(n=20)$ for analysis of HBI content. The remaining water containing ungrazed algae and faecal pellets was filtered (Whatman GF/F) and analysed for HBI content.

\subsection{Extraction and analysis of HBI lipids}

Extraction of HBI lipids was carried out on algal samples, Artemia sp. and filtered water as described previously (Brown et al., 2014a), and the subsequent analysis of purified non-polar extracts containing HBIs was carried out using gas chromatography-mass spectrometry (GCMS) techniques according to Belt et al. (2012).

\subsection{Calculation of the HBI biomarker H-Print}

HBI abundances were obtained from GC-MS selective ion monitoring (SIM) output (see Belt et al., 2012) using the mass spectral intensities of the molecular ion for each HBI (Brown et al., 2014d). Individual HBI abundances were normalised according to totals derived from all HBIs. The resulting distribution provided the basis for the H-Print (Brown et al., 2014d), which is defined, here, as the proportion of HBIs from pelagic diatoms relative to those from 
152

153

154

155

156

157

158

159

160

161

162

163

164

165

166

167

168

169

170

171

172

173

both sympagic and pelagic diatoms to provide H-Print values within the range $0-100 \%$ (Eq. 1).

Eq. 1.

$$
\mathrm{H}-\text { Print }(\%)=\frac{\text { (pelagic HBIs) }}{(\text { sympgaic HBIs }+ \text { pelagic HBIs })} \times 100
$$

To represent pelagic algae, 4 combinations of HBIs were tested. Firstly, for H-Print ${ }^{1}$, all HBI isomers, for which the chemical structures and at least one biological source organism were also known (Eq. 2), were used. For H-Print ${ }^{2}$ (Eq. 3), only V and VI were used, since these are the most common HBIs in phytoplankton (Belt et al., 2000). H-Print ${ }^{3-4}$ used only V, as it was absent from the sympagic algae (Eq. 4). To represent biomarkers of sympagic algae, I and III were chosen for H-Prints ${ }^{1-3}$ (Eq. 2-4) since these are the only HBIs in this study that are known to have a sea ice diatom source (Brown et al., 2014c). For H-Print ${ }^{4}$ (Eq. 5) only I was included as a sympagic component since it was not present in the pelagic algae.

Eq. 2.

$$
H-\operatorname{Print}^{1}(\%)=\frac{(\mathrm{II}+\mathrm{IV}+\mathrm{V}+\mathrm{VI}+\mathrm{VII}+\mathrm{VIII})}{(\mathrm{I}+\mathrm{II}+\mathrm{III}+\mathrm{IV}+\mathrm{V}+\mathrm{VI}+\mathrm{VII}+\mathrm{VIII})} \times 100
$$

Eq. 3.

$$
H-\operatorname{Print}^{2}(\%)=\frac{(\mathrm{V}+\mathrm{VI})}{(\mathrm{I}+\mathrm{III}+\mathrm{V}+\mathrm{VI})} \times 100
$$

Eq. 4.

$$
H-\operatorname{Print}^{3}(\%)=\frac{(\mathrm{V})}{(\mathrm{I}+\mathrm{III}+\mathrm{V})} \times 100
$$

$$
H-\operatorname{Print}^{4}(\%)=\frac{(\mathrm{V})}{(\mathrm{I}+\mathrm{V})} \times 100
$$


2.5 Statistical design

176

177 All experiments were carried out in replicate $(n=5)$ and, where Artemia sp. were involved, 178 each replicate contained 20 randomly selected individuals, resulting in 100 Artemia sp. being 179 used for each treatment. Statistical analysis was performed in R Studio v0.99.441 (R-Core180 Team, 2016). ANOVA was used to compare the H-Prints of algae, Artemia sp. and filtered 181 water for each treatment. Least squares regression fits were used for comparison of the 182 different H-Print equations across all treatments. Regression models were evaluated on the 183 basis of their ability to predict known algal composition. Predictions of the sympagic algae content of samples based on H-Prints was done using the 'predict()' function in base R with confidence intervals of $99 \%$. 
4 Results

\subsection{Quantification of HBIs and H-Prints in algae}

Samples of sympagic algae were dominated by HBIs I and III, which comprised $36 \pm 5 \%$ and $44 \pm 5 \%$ of total HBIs, respectively (Fig. 2). The remaining HBIs were, individually, all less than $10 \%$, while V and VIII were absent. In contrast, the most abundant HBI in the pelagic algae was V (33 $\pm 5 \%)$, with VI and VII contributing $15 \pm 3 \%$ and $20 \pm 2 \%$, respectively. Other HBIs were each less than 6\%, while I and IV were absent from pelagic algae (Fig. 2). For samples consisting exclusively of sympagic algae, calculations using Eq. $2-5$ resulted in $\mathrm{H}-$ Prints varying between 0-25\%, with Eq. 4 and Eq. 5 both giving H-Prints of $0 \pm 0 \%$, while Eq. 2 gave the highest values $(18 \pm 7 \%)$. For pelagic algae samples, the variability in H-Print values was much less (97-100\%), with Eq. 4 and Eq. 5 providing the lowest $(97 \pm 1 \%)$ and highest $(100 \pm 0 \%)$ values, respectively. For composite samples containing both sympagic and pelagic algae, H-Prints showed more variability than for end-member algae samples. For example, H-Prints from composite samples containing 50\% sympagic algae ranged from 42 to $80 \%$ with, on average, Eq. 4 giving the lowest $(53 \pm 8 \%)$ values. Highest values were obtained using Eq. $5(73 \pm 7 \%)$.

Regression models derived from Eq. 2, 3 and 5 provided estimates of 109-129\% sympagic algae for the sympagic end-member sample (Fig. 3, Table 1). The predictive model derived from Eq. 4 estimated the sympagic component to be $101 \%$. For the $50 \%$ sympagic algae sample, the models derived from Eq. 2, 3 and 5 gave estimates above the known sympagic contribution $(59 \%, 67 \%$ and $61 \%$, respectively), while Eq. 4 predicted 50\%. For pelagic endmember samples containing 0\% sympagic algae, models using Eq. 2, 3 and 4 all yielded low 
212 H-Prints (4\%, 6\% and -1\% sympagic algae, respectively), while prediction from the model

213 derived using Eq. 5 estimated a 13\% contribution from sympagic algae, even though it was

214 absent.

215

$216 \quad 4.2 \mathrm{H}$-Prints from analysis of Artemia sp. and filtered water samples

217

218 H-Print data, calculated using Eq. 4, for Artemia sp. and filtered water samples were not

219 significantly different from those obtained from algae for any of the sympagic/pelagic

220 compositions used ( $p=>0.3$ ). Accordingly, almost all of the H-Prints calculated for Artemia

221 sp. and filtered water fell well within the $99 \%$ confidence interval attached to the model

222 derived from mixed algae (Fig. 4a and 4b). 


\section{Discussion}

5.1 Selection of HBIs for use in the H-Print

227

In order to make comparisons of food source (as defined by the H-Print) in grazers more achievable, it was necessary to first identify the model that gave the most accurate relationship between H-Prints and the known algal composition. This selection focused on two main criteria; 1) accuracy of estimates and 2) confidence of the model. The most accurate model was derived from H-Print ${ }^{3}$ using I, III and V as the constituent HBIs, which estimated the sympagic and pelagic end-members at $101 \%$ and $-1 \%$, respectively (Table 1 ). In contrast, models derived from the other H-Prints (1,2 and 4) overestimated the sympagic component at $>109 \%$ and $>4 \%$ for the sympagic and pelagic end-members, respectively. In assessing the confidence intervals of the models, it was also found that the model using H-Print ${ }^{3}$ had the smallest mean confidence interval range (29; Table 1), indicating the least uncertainly of all composition from hereon.

5.2 Comparison of H-Prints in algae, filtered water and Artemia sp.

Having demonstrated that the H-Print could provide reliable estimates of the sympagic/pelagic proportion of mixed algal samples of known composition, it was then necessary to test whether the H-Print could also provide reasonable estimates of the sympagic/pelagic composition of algal food consumed by animals. To be successful, 
the H-Print. During the feeding experiments, there were no mortalities of Artemia sp., and the consistent, rapid appearance of visible faecal pellets indicated that non-selective grazing occurred for all experimental treatments. Experiments were run over $24 \mathrm{~h}$ to give Artemia sp. suitable opportunity to consume algae, and it is estimated that Artemia sp. consumed ca. $150 \%$ of the available algae during each experiment. This was determined by comparing the amount of HBI I in the $10 \mathrm{mg}$ sympagic algae supplied to Artemia sp. (ca. $0.59 \mu \mathrm{g}$ ), with that in pooled Artemia sp. after $24 \mathrm{~h}(\mathrm{ca} .0 .02 \mu \mathrm{g})$, which indicated that ca. $3 \%$ of the algae was present in the guts of Artemia sp. Based on an assumption of a gut passage time of 20-30 minutes (Nimura, 1989), it is estimated that ca. 50 gut passages per individual (ca. 1000 for 20 individuals) occurred over the duration of each experiment, potentially resulting in $15 \mathrm{mg}$ (150\%) algae being consumed. This outcome is supported by the experiments of Reeve (1963) who showed that Artemia sp. consumed Phaeodactylum tricornutum at ca. 4x10 5 cells $\mathrm{h}^{-1}$, which, over $24 \mathrm{~h}$, corresponds to ca. $300 \%$ of our $3.1 \times 10^{6}$ cell $\mathrm{L}^{-1}$, and seems quite feasible given the tendency for coprophagy in captive zooplankton (Werner, 2000). Despite the efficient grazing of sympagic algae in the current experiments, Artemia sp. did not alter the relative distributions of individual HBI biomarkers. Indeed, the majority (80\%) of mean H-Prints derived from water and Artemia sp. fell within the $99 \%$ confidence interval of the regression model calculated using the algal H-Print ${ }^{3}$ (Fig. 4b), suggesting that Artemia sp. grazed non-selectively on all treatments, without alteration of the H-Print. It is concluded, therefore, that the regression model, based upon algal H-Prints, remains accurate for Artemia sp., permitting application of the regression model to predict the sympagic/pelagic proportion of zooplankton diet.

\subsection{Environmental application of the H-Print}


Although it has been shown here that the H-Print approach can yield reliable estimates of the sympagic/pelagic composition of algae in the laboratory, even after being consumed by zooplankton, it is probably also important to consider some additional factors that may be important when using this method in environmental settings in the future. Three such factors are considered briefly here. Firstly, HBIs should be readily detectable in the environment. Recently, the ubiquity of HBIs has been established following the widespread reporting of these lipids in, for example, sea ice (Belt et al., 2007,2013,2016; Brown et al., 2011; Massé et al., 2011; Nichols et al., 1988), sediments (Belt and Müller, 2013; Navarro-Rodriguez et al., 2013; Xiao et al., 2015), zooplankton (Brown and Belt, 2012; Cripps, 1995), fish (Brown et al., 2015; Goutte et al., 2014b), birds (Brown et al., 2013a,2015) and marine mammals (Brown, et al., 2013a,2014a; Goutte et al., 2014a) from Arctic, Antarctic and temperate environments. Second, it is suggested that identification of the H-Print formula that best reflects the composition of natural sympagic and pelagic algae may also be important. In the current study, it was shown that a key factor in identifying such a formula was selection of HBIs that provide a balanced contribution from sympagic and pelagic sources. Achieving this balance is, to some extent, simplified by the shared ability of sympagic and pelagic algae to biosynthesise HBIs, thereby minimising any potential complications associated with comparing lipids from different sources; a problem frequently associated with more common lipids such as fatty acids or sterols which can have a wide range of sources (e.g. Natalia et al., 1999; Volkman et al., 1986,1998), including, in some cases, animals themselves.

Nonetheless, the proportion of sympagic/pelagic HBIs will be dependent upon the overall abundances of HBI-biosynthesising diatoms present. On this basis, it is anticipated that $\mathrm{H}$ Print $^{3}$ may, as it did in the experiments described herein, provide the most realistic estimates for environmental samples, since the species known to produce I, III and V have similar abundances in the environment. For example, the diatoms that produce I and III have a 
consistent abundance in sea ice throughout the Arctic (1-5\%; Brown et al., 2014c and references therein), while Pleurosigma spp. and Rhizosolenia spp. (known sources of V) are also typically $1-5 \%$ of species in pelagic diatom assemblages (Mather et al., 2010; von Quillfeldt, 2000). On the other hand, if the abundances of the sympagic or pelagic sources should differ substantially from this, it is possible that H-Print ${ }^{3}$ may not be the best predictor of algal composition and a different combination of HBIs may give more reliable estimates. In order to obtain the most reliable estimates of algal composition in samples collected from the environment, it is therefore recommended that H-Prints for both sympagic and pelagic algae are determined on a case-by-case basis using samples collected from the environment being studied. Accordingly, the appropriate model can thus be selected that best estimates the composition of mixed algae samples.

Finally, differential modification of HBI lipid distributions within animals would likely result in inaccurate estimates of algae composition, regardless of which H-Print formula is used. As such, it is important that, once consumed by animals, HBIs do not become modified from their original source distributions, as was the case for Artemia sp. described herein. In the Arctic, the most abundant zooplankton are usually Calanus spp. (Auel and Hagen, 2002; Søreide et al., 2008) and, in contrast to Artemia sp., these do accumulate lipids (Graeve et al., 2005; Pond and Tarling, 2011). The close similarity of Calanus spp. H-Prints with those from pelagic algae (Brown et al., 2014d), however, in addition to those between some higher trophic level organisms and sympagic algae (Brown et al., 2014d), suggest that HBI distributions are not noticeably impacted by animals. Indeed, quantitative assessment of the relative proportions of I and III in over 300 ringed seals showed a consistent ratio $(1: 2.7)$ that aligned closely to typical values from sea ice (e.g. 1:2.1 (Belt et al., 2013) and 1:2.9 (Brown, 2011)), further supporting the finding here that H-Prints are unlikely to be significantly 
altered by animals. Confirmation of this, however, will likely require further analyses of larger sample sets that focus on Arctic animals feeding on prey with known H-Print signatures.

In summary, the data presented herein demonstrate that the biomarker-based H-Print has the potential to provide reliable, quantitative predictions of the sympagic/pelagic composition of animal diet. This conclusion is based upon a series of controlled laboratory experiments from which, first, a linear regression model was created, where H-print values reflected the relative proportions of sympagic and pelagic algae in mixtures of known composition. In addition, there was no significant difference in the numerical values of $\mathrm{H}$-Prints measured in these samples of mixed algae and in zooplankton that had been fed these food sources. The potential for the H-Print method to provide quantitative estimates of the role that sympagic algae play in animal diet will likely lead to valuable new field data for modelling the broader ecological impacts of reducing Arctic sea ice extent. 
340 Acknowledgements

341 This work was supported by a Leverhulme Trust Research Project Grant (RPG-2014-021).

342 The authors also thank Sandra Shumway and an anonymous reviewer for providing

343 supportive feedback on the manuscript. 
References

Arrigo, K.R., 2014. Sea Ice Ecosystems. Ann. Rev. Mar. Sci. 6, 439-467.

Auel, H., Hagen, W., 2002. Mesozooplankton community structure, abundance and biomass in the central Arctic Ocean. Mar. Biol. 140, 1013-1021.

Belt, S.T., Müller, J., 2013. The Arctic sea ice biomarker $\mathrm{IP}_{25}$ : a review of current understanding, recommendations for future research and applications in palaeo sea ice reconstructions. Quat. Sci. Rev. 79, 9-25.

Belt, S.T., Allard, W.G., Massé, G., Robert, J.M., Rowland, S.J., 2000. Highly branched isoprenoids (HBIs): Identification of the most common and abundant sedimentary isomers. Geochim. Cosmochim. Acta 64, 3839-3851.

Belt, S.T., Massé, G., Rowland, S.J., Poulin, M., Michel, C., LeBlanc, B., 2007. A novel chemical fossil of palaeo sea ice: $\mathrm{IP}_{25}$. Org. Geochem. 38, 16-27.

Belt, S.T., Massé, G., Vare, L.L., Rowland, S.J., Poulin, M., Sicre, M.-A., Sampei, M., Fortier, L., 2008. Distinctive ${ }^{13} \mathrm{C}$ isotopic signature distinguishes a novel sea ice biomarker in Arctic sediments and sediment traps. Mar. Chem. 112, 158-167.

Belt, S.T., Brown, T.A., Navarro-Rodriguez, A., Cabedo-Sanz, P., Tonkin, A., Ingle, R., 2012. A reproducible method for the extraction, identification and quantification of the Arctic sea ice proxy $\mathrm{IP}_{25}$ from marine sediments. Anal. Methods 4, 705-713.

Belt, S.T., Brown, T.A., Ringrose, A.E., Cabedo-Sanz, P., Mundy, C.J., Gosselin, M., Poulin, M., 2013. Quantitative measurement of the sea ice diatom biomarker $\mathrm{IP}_{25}$ and sterols in Arctic sea ice and underlying sediments: further considerations for palaeo sea ice reconstruction. Org. Geochem. 62, 33-45.

Belt, S.T., Cabedo-Sanz, P., Smik, L., Navarro-Rodriguez, A., Berben, S.M.P., Knies, J., Husum, K., 2015. Identification of paleo Arctic winter sea ice limits and the marginal 
ice zone: Optimised biomarker-based reconstructions of late Quaternary Arctic sea ice. Earth Planet. Sci. Lett. 431, 127-139.

Belt, S.T., Smik, L., Brown, T.A., Kim, J.-H., Rowland, S.J., Allen, C.S., Gal, J.-K., Shin, K.-H., Lee, J.I., Taylor, K.W.R., 2016. Source identification and distribution reveals the potential of the geochemical Antarctic sea ice proxy $\mathrm{IPSO}_{25}$. Nat. Commun. 7,12655 .

Brown, T.A., 2011. Production and preservation of the Arctic sea ice diatom biomarker $\mathrm{IP}_{25}$. PhD Thesis, School of Geography Earth and Environmental Sciences. University of Plymouth, Plymouth.

Brown, T.A., Belt, S.T., Philippe, B., Mundy, C.J., Massé, G., Poulin, M., Gosselin, M., 2011. Temporal and vertical variations of lipid biomarkers during a bottom ice diatom bloom in the Canadian Beaufort Sea: Further evidence for the use of the $\mathrm{IP}_{25}$ biomarker as a proxy for spring Arctic sea ice. Polar Biol. 34, 1857-1868.

Brown, T.A., Belt, S.T., 2012. Closely linked sea ice-pelagic coupling in the Amundsen Gulf revealed by the sea ice diatom biomarker $\mathrm{IP}_{25}$. J. Plankton Res. 34, 647-654.

Brown, T.A., Belt, S.T., Ferguson, S.H., Yurkowski, D.J., Davison, N.J., Barnett, J.E.F., Jepson, P.D., 2013a. Identification of the sea ice diatom biomarker $\mathrm{IP}_{25}$ and related lipids in marine mammals: A potential method for investigating regional variations in dietary sources within higher trophic level marine systems. J. Exp. Mar. Biol. Ecol. 441, 99-104.

Brown, T.A., Bicknell, A.W.J., Votier, S.C., Belt, S.T., 2013b. Novel molecular fingerprinting of marine avian diet provides a tool for gaining insights into feeding ecology. Environ. Chem. Lett. 11, 283-288.

Brown, T.A., Alexander, C., Yurkowski, D.J., Ferguson, S., Belt, S.T., 2014a. Identifying variable sea ice carbon contributions to the Arctic ecosystem: A case study using 
highly branched isoprenoid lipid biomarkers in Cumberland Sound ringed seals. Limnol. Oceanogr. 59, 1581-1589.

Brown, T.A., Belt, S.T., Cabedo-Sanz, P., 2014b. Identification of a novel di-unsaturated $\mathrm{C}_{25}$ highly branched isoprenoid in the marine tube-dwelling diatom Berkeleya rutilans. Environ. Chem. Lett. 12, 455-460.

Brown, T.A., Belt, S.T., Tatarek, A., Mundy, C.J., 2014c. Source identification of the Arctic sea ice proxy $\mathrm{IP}_{25}$. Nat. Commun. 5, 4197.

Brown, T.A., Yurkowski, D.J., Ferguson, S.H., Alexander, C., Belt, S.T., 2014d. H-Print: a new chemical fingerprinting approach for distinguishing primary production sources in Arctic ecosystems. Environ. Chem. Lett. 12, 387-392.

Brown, T.A., Hegseth, E.N., Belt, S.T., 2015. A biomarker-based investigation of the midwinter ecosystem in Rijpfjorden, Svalbard. Polar Biol. 38, 37-50.

Brown, T.A., Belt, S.T., 2016. Novel tri- and tetra-unsaturated highly branched isoprenoid (HBI) alkenes from the marine diatom Pleurosigma intermedium. Org. Geochem. 91, $120-122$.

Cooke, D.A., Barlow, R., Green, J., Belt, S.T., Rowland, S.J., 1998. Seasonal variations of highly branched isoprenoid hydrocarbons and pigment biomarkers in intertidal sediments of the Tamar Estuary, UK. Mar. Environ. Res. 45, 309-324.

Cripps, G.C., 1995. The occurrence of monounsaturated $n-C_{21}$ and polyunsaturated $\mathrm{C}_{25}$ sedimentary hydrocarbons in the lipids of Antarctic marine organisms. Polar Biol. 15, $253-259$.

da Costa, R.A.A.M., Koening, M.L., Pereira, L.C.C., 2005. Feeding adult of Artemia salina (Crustacea-Branchiopoda) on the dinoflagellate Gyrodinium corsicum (Gymnodiniales) and the Chryptophyta Rhodomonas baltica. Braz. Arch. Biol. Technol. 48, 581-587. 
Dieckmann, G.S., Hellmer, H.H., 2010. The importance of sea ice: An overview. In: Thomas, D., Dieckmann, S. (Eds.), Sea ice (second edition). Blackwell Publishing, Chichester, pp. 1-22.

Dunlop, R.W., Jefferies, P.R., 1985. Hydrocarbons of the hypersaline basins of Shark Bay, Western-Australia. Org. Geochem. 8, 313-320.

Evjemo, J.O., Olsen, Y., 1999. Effect of food concentration on the growth and production rate of Artemia franciscana feeding on algae (T. iso). J. Exp. Mar. Biol. Ecol. 242, 273-296.

Goutte, A., Charrassin, J.B., Cherel, Y., Carravieri, A., De Grissac, S., Masse, G., 2014a. Importance of ice algal production for top predators: new insights using sea-ice biomarkers. Mar. Ecol. Prog. Ser. 513, 269-275.

Goutte, A., Cherel, Y., Ozouf-Costaz, C., Robineau, C., Lanshere, J., Massé, G., 2014b. Contribution of sea ice organic matter in the diet of Antarctic fishes: a diatom-specific highly branched isoprenoid approach. Polar Biol. 37, 903-910.

Graeve, M., Albers, C., Kattner, G., 2005. Assimilation and biosynthesis of lipids in Arctic Calanus species based on feeding experiments with a ${ }^{13} \mathrm{C}$ labelled diatom. J. Exp. Mar. Biol. Ecol. 317, 109-125.

Grossi, V., Beker, B., Geenevasen, J.A.J., Schouten, S., Raphel, D., Fontaine, M.-F., Sinninghe Damsté, J.S., 2004. $\mathrm{C}_{25}$ highly branched isoprenoid alkene from the marine benthic diatom Pleurosigma strigosum. Phytochemistry 65, 3049-3055.

He, D., Simoneit, B.R.T., Xu, Y., Jaffé, R., 2016. Occurrence of unsaturated $\mathrm{C}_{25}$ highly branched isoprenoids (HBIs) in a freshwater wetland. Org. Geochem. 93, 59-67.

Kaiser, J., Belt, S.T., Tomczak, M., Brown, T.A., Wasmund, N., Arz, H.W., 2016. C25 highly branched isoprenoid alkenes in the Baltic Sea produced by the marine planktonic diatom Pseudosolenia calcar-avis. Org. Geochem. 93, 51-58. 
Massé, G., Belt, S.T., Crosta, X., Schmidt, S., Snape, I., Thomas, D.N., Rowland, S.J., 2011. Highly branched isoprenoids as proxies for variable sea ice conditions in the Southern Ocean. Antarct. Sci. 23, 487-498.

Mather, L., MacIntosh, K., Kaczmarska, I., Klein, G., Martin, J.L., 2010. A checklist of diatom species reported (and presumed native) from Canadian coastal waters. Can. Tech. Rep. Fish. Aquat. Sci. 1-78.

Meier, W.N., Hovelsrud, G.K., van Oort, B.E.H., Key, J.R., Kovacs, K.M., Michel, C., Haas, C., Granskog, M.A., Gerland, S., Perovich, D.K., Makshtas, A., Reist, J.D., 2014. Arctic sea ice in transformation: A review of recent observed changes and impacts on biology and human activity. Rev. Geophys. 2013RG000431.

Müller, J., Massé, G., Stein, R., Belt, S.T., 2009. Variability of sea-ice conditions in the Fram Strait over the past 30,000 years. Nat. Geosci. 2, 772-776.

Müller, J., Werner, K., Stein, R., Fahl, K., Moros, M., Jansen, E., 2012. Holocene cooling culminates in sea ice oscillations in Fram Strait. Quat. Sci. Rev. 47, 1-14.

Natalia, V. Z., and I. K. Vladimir. 1999. Sources of essential fatty acids in the marine microbial loop. Aquat. Microb. Ecol. 17, 153-157.

Navarro-Rodriguez, A., Belt, S.T., Knies, J., Brown, T.A., 2013. Mapping recent sea ice conditions in the Barents Sea using the proxy biomarker IP $_{25}$ : implications for palaeo sea ice reconstructions. Quat. Sci. Rev. 79, 26-39.

Nichols, P.D., Palmisano, A.C., Volkman, J.K., Smith, G.A., White, D.C., 1988. Occurrence of an isoprenoid $\mathrm{C}_{25}$ diunsaturated alkene and high neutral lipid content in Antarctic sea-ice diatom communities. J. Phycol. 24, 90-96.

Nimura, Y., 1989. Shortest gut passage time and gut content volume of Artemia franciscana. Nippon Suisan Gakkaishi 55, 2209-2209. 
Polyak, L., Belt, S.T., Cabedo-Sanz, P., Yamamoto, M., Park, Y.-H., 2016. Holocene sea-ice conditions and circulation at the Chukchi-Alaskan margin, Arctic Ocean, inferred from biomarker proxies. Holocene 26, 1810-1821.

Pond, D.W., Tarling, G.A., 2011. Phase transitions of wax esters adjust buoyancy in diapausing Calanoides acutus. Limnol. Oceanogr. 56, 1310-1318.

R-Core-Team, 2016. R: A language and environment for statistical computing, R Foundation for Statistical Computing, Vienna, Austria, pp. URL http://www.R-project.org/.

Reeve, M.R., 1963. The Filter-Feeding of Artemia. I. In Pure Cultures of Plant Cells 40, 195205.

Rowland, S.J., Allard, W.G., Belt, S.T., Massé, G., Robert, J.M., Blackburn, S., Frampton, D., Revill, A.T., Volkman, J.K., 2001. Factors influencing the distribution of polyunsaturated terpenoids in the diatom, Rhizosolenia setigera. Phytochemistry 58, $717-728$.

Smik, L., Cabedo-Sanz, P., Belt, S.T., 2016. Semi-quantitative estimates of paleo Arctic sea ice concentration based on source-specific highly branched isoprenoid alkenes: A further development of the PIP 25 index. Org. Geochem. 92, 63-69.

Søreide, J.E., Falk-Petersen, S., Hegseth, E.N., Hop, H., Carroll, M.L., Hobson, K.A., Blachowiak-Samolyk, K., 2008. Seasonal feeding strategies of Calanus in the highArctic Svalbard region. Deep-Sea Res. Pt. II 55, 2225-2244.

Stein, R., Fahl, K., Schreck, M., Knorr, G., Niessen, F., Forwick, M., Gebhardt, C., Jensen, L., Kaminski, M., Kopf, A., Matthiessen, J., Jokat, W., Lohmann, G., 2016. Evidence for ice-free summers in the late Miocene central Arctic Ocean. Nat. Commun. 7, 11148.

Stoynova, V., Shanahan, T.M., Hughen, K.A., de Vernal, A., 2013. Insights into CircumArctic sea ice variability from molecular geochemistry. Quat. Sci. Rev. 79, 63-73. 
Stroeve, J.C., Kattsov, V., Barrett, A., Serreze, M., Pavlova, T., Holland, M., Meier, W.N., 2012. Trends in Arctic sea ice extent from CMIP5, CMIP3 and observations. Geophys. Res. Lett. 39.

Vare, L.L., Massé, G., Gregory, T.R., Smart, C.W., Belt, S.T., 2009. Sea ice variations in the central Canadian Arctic Archipelago during the Holocene. Quat. Sci Rev. 28, 13541366.

Volkman, J. K. 1986. A review of sterol markers for marine and terrigenous organic matter. Org. Geochem. 9, 83-99.

Volkman, J. K., Barrett, S.M., Blackburn, S.I., Mansour, M.P., Sikes, E.L., Gelin, F., 1998. Microalgal biomarkers: A review of recent research developments. Org. Geochem. $29,1163-1179$.

Volkman, J.K., Barrett, S.M., Dunstan, G.A., 1994. $C_{25}$ and $C_{30}$ highly branched isoprenoid alkenes in laboratory cultures of two marine diatoms. Organic Geochemistry 21, 407414.

von Quillfeldt, C.H., 2000. Common Diatom Species in Arctic Spring Blooms: Their Distribution and Abundance, Botanica Marina, pp. 499.

Werner, I., 2000. Faecal pellet production by Arctic under-ice amphipods-transfer of organic matter through the ice/water interface. Hydrobiologia 426, 89-96.

Wraige, E.J., Belt, S.T., Lewis, C.A., Cooke, D.A., Robert, J.M., Massé, G., Rowland, S.J., 1997. Variations in structures and distributions of $\mathrm{C}_{25}$ highly branched isoprenoid (HBI) alkenes in cultures of the diatom, Haslea ostrearia (Simonsen). Org. Geochem. 27, 497-505.

Xiao, X., Fahl, K., Müller, J., Stein, R., 2015. Sea-ice distribution in the modern Arctic Ocean: Biomarker records from trans-Arctic Ocean surface sediments. Geochim. Cosmochim. Acta 155, 16-29. 
517 Xu, Y., Jaffé, R., Wachnicka, A., Gaiser, E.E., 2006. Occurrence of $\mathrm{C}_{25}$ highly branched isoprenoids (HBIs) in Florida Bay: Paleoenvironmental indicators of diatom-derived organic matter inputs. Org. Geochem. 37, 847-859.

520

521

522 
523 Table 1. Estimates of the sympagic contribution to mixed sympagic/pelagic algae samples

\begin{tabular}{|c|c|c|c|c|c|c|c|c|c|}
\hline & $\begin{array}{c}\text { H-Print } \\
\text { Eq.\# }\end{array}$ & $R^{2}$ & $\begin{array}{c}\text { Residual } \\
\text { (se) }\end{array}$ & $d f$ & $p$ & $\begin{array}{r}\text { Model estir } \\
(95 \%\end{array}$ & ates of sympa & $\begin{array}{l}\text { ic contribution } \\
\text { te algae }\end{array}$ & $\begin{array}{c}\text { Mean CI } \\
\text { range }\end{array}$ \\
\hline$(\mathrm{S}: \mathbf{P})$ & & & & & & $0: 100$ & $50: 50$ & 100:0 & \\
\hline H-Print ${ }^{1}$ & 2 & 0.95 & 8.6 & 23 & $<0.01$ & $4(-14-23)$ & $59(41-77)$ & $113(95-133)$ & 37 \\
\hline H-Print ${ }^{2}$ & 3 & 0.92 & 10.4 & 23 & $<0.01$ & $6(-16-29)$ & $67(45-89)$ & $129(104-153)$ & 46 \\
\hline H-Print ${ }^{3}$ & 4 & 0.97 & 6.6 & 23 & $<0.01$ & $-1(-16-14)$ & $50(36-64)$ & $101(87-116)$ & 29 \\
\hline H-Print ${ }^{4}$ & 5 & 0.89 & 11.7 & 23 & $<0.01$ & $13(-11-39)$ & $61(37-86)$ & $109(83-135)$ & 50 \\
\hline
\end{tabular}

524

525 
$526 \quad$ Figure legends

527 Figure 1. Structures of diatom highly branched isoprenoid (HBI) lipid biomarkers described 528 in this study.

529

530 Figure 2. Relative proportions of highly branched isoprenoids (HBIs) in sympagic and 531 pelagic algae used in this study.

533 Figure 3. Mean H-Print $( \pm \mathrm{SE})$ of algae samples containing sympagic and pelagic algae

534 calculated using Eq. 2-5. Horizontal dashed lines show mean H-Prints calculated for samples

535 containing 50\% sympagic and 50\% pelagic algae. Solid coloured lines are linear least squares regression fits to data points for each H-Print.

537

538 Figure 4. a) Mean H-Print ${ }^{3}( \pm$ SE) of algae samples containing sympagic and pelagic algae.

539 Straight line $\left(\mathrm{R}^{2}=0.97 ; p=<0.001\right)$ regression fit using H-Print ${ }^{3}$ of food with 0.99

540 confidence interval (SE) with regression formula shown. Horizontal and vertical dashed lines

541 refer to 50:50 sympagic:pelagic and 50\% H-Print. b) Mean H-Print ${ }^{3}( \pm$ SE) of Artemia sp.

542 (triangles) and filtered water (down triangles) calculated with H-Print ${ }^{3}$. Shaded area shows

543 upper and lower CI from H-Print ${ }^{3}$ algae regression model from panel a. 
<smiles>C=CC(C)CCC(CCC(C)CCCC(C)C)C(C)CCCC(C)C</smiles><smiles>C=CC(C)CCC(CCC(C)CCCC(C)C)/C(C)=C/CCC(C)C</smiles><smiles>C=CC(C)CCC(CCC(C)CCCC(C)C)C(=C)CCCC(C)C</smiles><smiles>C=CC(C)C/C=C(\CCC(C)CCCC(C)C)C(C)CCCC(C)C</smiles><smiles>C=CC(C)C/C=C(\C/C=C(/C)CCCC(C)C)C(C)CCCC(C)C</smiles><smiles>C=CC(C)C/C=C(\C/C=C(\C)CCCC(C)C)C(C)CCCC(C)C</smiles><smiles>C=CC(C)CCC(C/C=C(\C)CCCC(C)C)/C(C)=C\CCC(C)C</smiles><smiles>C=CC(C)CCC(CC=C(C)CCC=C(C)C)C(C)=CCC=C(C)C</smiles> 


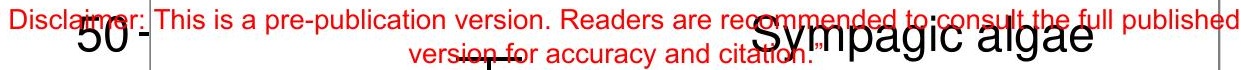

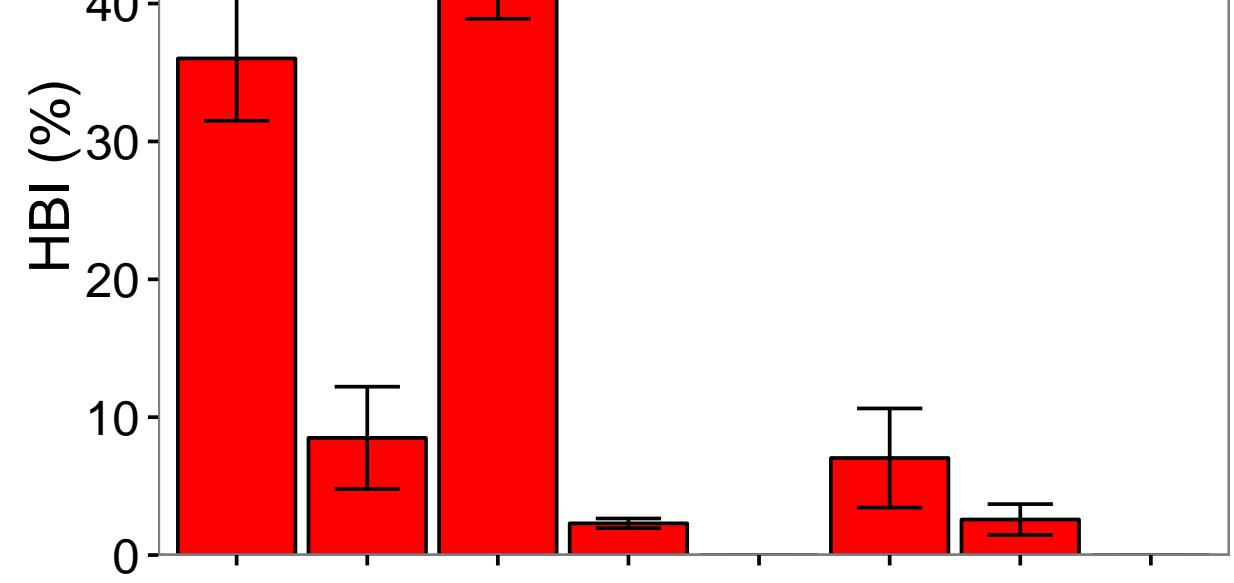

50

Pelagic algae

$40-$

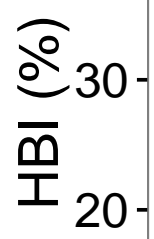

10

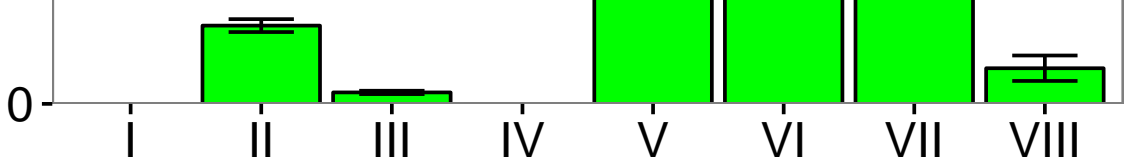


" Disclaimer: This is a pre-publication version. Readers are recommended to consult the full published version for accuracy and citation."

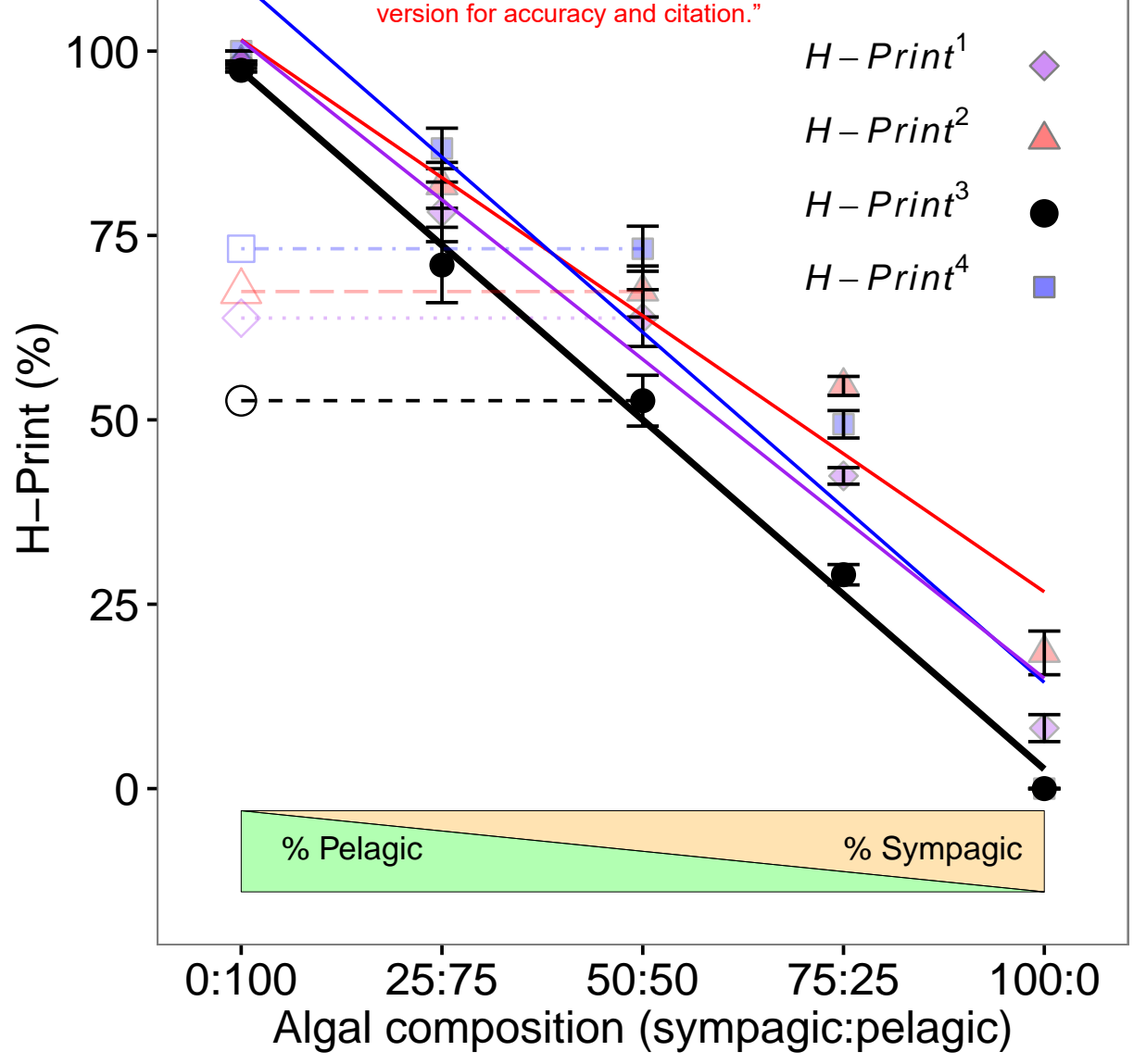



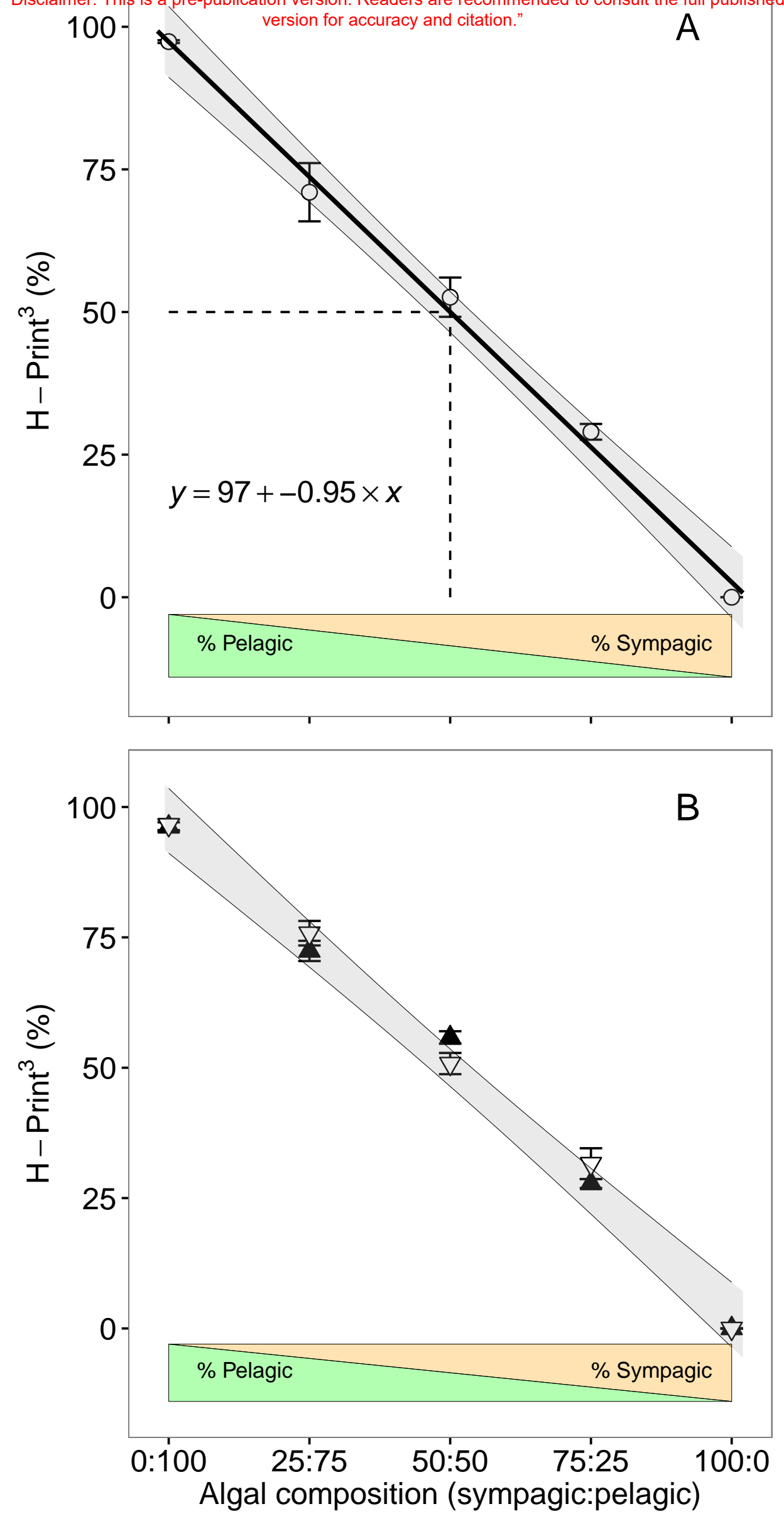